\title{
Erratum to: Organizing preliminary storage sites of organic material, waste fuels and recyclables and their separating distance from populated areas
}

\author{
Muhammad Asim Ibrahim • William Hogland
}

Published online: 8 January 2014

(C) Springer Japan 2013

Erratum to: J Mater Cycles Waste Manag

DOI 10.1007/s10163-013-0184-z

The following errors appeared in this article.

In the text of the "Results" section, under the heading "Sensitivity analysis", there are eight occurrences of

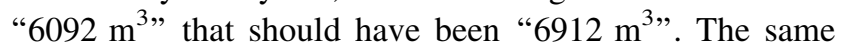
error occurs in Table 2 and in Fig. 3a. Also under "Sensitivity analysis" of the "Results" section, "Figs. 2a/d, b/e, c/d" should have been "Figs. 2a/d, b/e, c/f".

The authors regret the errors.

The online version of the original article can be found under doi:10.1007/s10163-013-0184-z.

M. A. Ibrahim ( $\square) \cdot$ W. Hogland

Department of Biology and Environmental Science, Faculty of Health and Life Sciences, Linnaeus University, 39182 Kalmar, Sweden

e-mail: asim.ibrahim@lnu.se

W. Hogland

e-mail: william.hogland@lnu.se 